\title{
Accentuating institutional brands: A multimodal analysis of the homepages of selected South African universities
}

\author{
L. Mafofo and F. Banda
}

\begin{abstract}
:
In seeking to disentangle themselves from the constraints of apartheid, South African universities have immersed themselves in an identity modification process in which they not only seek to redress the past, but also to reposition their identities as equal opportunity and non-racial institutions. In this paper, we investigate how the University of the Western Cape, the University of Cape Town and Stellenbosch University have used visual and verbal semiotics to re-design their identities on their homepages to appeal to diverse national and international clients. Using Multimodal Discourse Analysis (MDA), we show how the multi-semiotic choices work together on the homepages to give the universities differentiated, competitive, powerful and attractive brands. We conclude that the homepages blended cultural semiotic artefacts, historical, global and transformational discourses, and architectural landscapes to construct different brand identities that, in turn, rebrand the universities from edifices of apartheid education to equal opportunity institutions.
\end{abstract}

\section{Introduction}

In the contemporary world, especially in developing countries, academic institutions are increasingly making strenuous efforts to present themselves as desirable institutions in order to be visible globally. As part of these efforts, such institutions undertake various promotional activities by using linguistic and visual means, for instance slogans, logos, photographs and promotional films. In doing so, they draw not only on the pre-existent landscapes to be represented in promotional materials, but also on the public discourses implemented in creating and maintaining their identities. As a result, the current literature on the process of marketisation within academia claims that there is a notable universal tendency by public universities to use governance, management and discourse styles associated with the corporate sector (Fairclough 1993, Gee 1999, Mautner 2005, Osman 2006). Studies have also shown an increase in the rhetoric of the free market, which is normally found in business-related texts, in the discursive repertoire employed by academic leaders. Most of these studies have focused on institutions of higher learning in the developed West and have generalised their findings as applicable to the universities in the rest of the world. Nevertheless, considering the difference in status and background between educational institutions in developed and developing countries, there is a need to 
investigate whether or not the findings noted above hold true for the latter. It should, however, be noted that people from different communities and historical backgrounds are invariably not uniform in terms of aspirations and socio-economic needs. Consequently, marketisation discourses that work in developed countries may not necessarily have the same effect in developing countries. The focus in this paper is on how selected South African universities have accentuated their brands on their homepages in a bid to reach out to local, regional and international stakeholders. Since the universities selected for the study comprise an historically black university (HBU), the University of the Western Cape (UWC), and two historically white universities (HWUs), the University of Cape Town (UCT) and Stellenbosch University (SU), the paper also explore how these universities have utilised the different socio-cultural and historical accounts and marketisation discourses of globalisation to transform themselves from edifices of apartheid education to equal opportunity institutions.

\section{The historical apartheid trajectory and the democratic situation in the universities}

All three universities in this study were established under the repressive segregationists conditions prevailing in South Africa at the time. UWC was established in 1959 as one of the 'bush universities' for coloured students, and to offer clerical and manual labour for whites (Gerhart 1978). It was designed to perform a particular role in the reproduction of apartheid as trained coloured student only in particular restricted fields, which were 'relative to occupations in the middle rather than the upper reaches of the stratification system' (Wolpe 1995: 283). Conversely, UCT was founded in 1829 as the then South African College. Initially it was a college for white boys, but evolved and became a white university, UCT, in 1918 on the basis of the Alfred Beit inheritance, and additional generous gifts and state grants from Julius Wenher and Otto Beit (mining tycoons) and the Cape Town society (Gerhart 1978). Although UCT was for whites, it had an open policy in which non-whites were accepted in limited numbers. This policy was however continuously contested especially when the apartheid regime passed the Extension of University Education Act in 1959. SU on the other hand was first established as Victoria College in 1865 and changed to its current name in 1918. It was opened because the white Afrikaner elite was determined to establish its own university as a part of the nationalist conflict with the English (Gerhart 1978).

Just as the forces of apartheid had shaped these universities, particularly after 1960 through to the late 1980s, after 1994 they all faced challenges of how to change and redefine themselves in the post-apartheid South Africa. They had to realign their institutional strategies and policies in terms of staffing and student demographics, with the new higher education development policy documents, such as the Higher Education Act No. 101 of 1997, which required them to move towards implementing an inclusive democratic education system that fosters greater participation. These pressures compelled the universities to take a relook at their mission statements to capture the ethos of the new South African dispensation in a globalised world through what Fairclough (2002) calls 
the language of new capitalism - with tendencies towards appropriation and re-articulation of discourses of marketisation in higher education.

Two decades after the birth of democracy, South African higher education institutions still face many challenges but there have been remarkable changes and successes in transformation. Since the transformation of higher education began in the mid-1990s, the binary divide has been dismantled, the number of students in South Africa's public universities has doubled and the racial make-up of the student body has radically improved. For instance, the rigid, racially exclusive universities no longer exist as the resource-rich, preserve of white students. And the former Afrikaans-language universities, such as SU, are now attracting increasing numbers of students from a range of language and cultural backgrounds to be part of their university community (Bawa and Herwitz, 2008). There has also been a fair response to the current government call for the universities to become ever more responsive to the educational needs of the socio-economically challenged sectors of the South African populace, as well as to the need for the mobility of the student and academic community as global citizens. Although still insufficient to result in full-scale redress, the three universities in this study have put measures in place, such as academic writing programmes, throughput centres and bursaries offices, to help students in need. Transformation of higher education in the universities is therefore being tackled from the broader cultural, political, social and economic transition (Reddy 2004).

Although the main positive transformative success is more evident in the de-racialisation of students, the challenges of inequalities of geographical locations and life styles remain (see Odhav 2009). Diversity also disguises some of these inequalities and this sees HBUs battling to justify their continued struggle to move away from the imposed identities of the past and realign themselves to the more globally favourable and functional identities (Bawa and Herwitz 2008) associated with high quality research and academic excellence. As Lalu and Murray (2012) argue, even the ironic emptying of the HBU's apartheid identity and historical struggles into the discourse of nationalism and globalism poses new challenges for how to speak of their current and future identity. As such, development between the HWUs and HBUs remain uneven with the former sharing modern facilities and top researchers while the latter play catch up through developing their own human and institutional capacities by attracting high calibre academics and building modern infrastructure. The forces of globalisation do not make it easy either, as the inherited inequalities in development have caused massive differences in wealth among the universities and citizens accessing resources in these universities.

The three universities focused on in this study find themselves on a new and rapidly changing playing field. This also emerges from worldwide trends, such as the acceleration of information generation and the knowledge revolution. For instance, the acceleration of information generation and the creation of new knowledge are more prominent at the centre of economic growth and development. This trend poses new demands, opportunities and risks for universities. Another trend is the increasing of internationalisation, which is promoting the worldwide mobility of people, knowledge and 
ideas, and is coupled with demands on and opportunities for universities all over the world. Obviously, these new challenges mean that universities are getting increased opportunities to enhance their relevance. At the same time, however, these new challenges create the potential for conflict with the institutional characteristics of the universities, giving rise to the need to examine the efforts they are making and the methods they are using to rebrand themselves, especially in the context of their conflicting backgrounds and their current environments.

Apart from these challenges, the new democratic South African government is increasingly exercising strategic influence on higher education through earmarked or performance-based funding systems, reporting requirements and statutory and consultative bodies (Wolpe 1995). Therefore, the present competitive efforts by the South African universities to protect their existing privilege or to gain ground in the postapartheid South Africa must to some extent be in line with restructuring government plans highlighted in the National Commission on Higher Education (NCHE). The Commission was established in 1998 following the Higher Education Act, No. 101 of 1997. It was, among other things, charged with the task of ensuring quality and restructuring of higher education from the race-based institutions to equal opportunity universities.

Although the Commission provides a more or less unified framework within which the different institutions could begin to reorganise and redefine their roles within the new social order, each institution has, of course, its own specific history and characteristics. Therefore, the strategic issue for the institutions was how to transform themselves both in the light of the Commission's framework and their own histories, while reconstructing new and differentiated identities for marketing purposes.

\section{The study}

Following Fairclough (2003) and O'Halloran (2004), the present study is a text-based multimodal discourse analysis. Homepages from the websites of the three universities constitute the texts analysed. They are sets of interpretive material practices that make visible the world of the universities concerned. Hence, this paper followed the interpretive paradigm, which sees the social world as a process that is created by individuals. Social reality, as it exists outside the consciousness of any individual, is regarded as a network of assumptions and inter-subjectively shared meanings (Morgan 1983). These assumptions lead to the belief that there are shared multiple realities which are sustained or changed depending on the reality being discursively created at a particular time. The goal of interpretive research is thus to find the types of articulations or configurations of genres, discourses and styles, that is, the social structuring of semiotic difference or variation in social contexts. Consequently, the interpretative research enabled an examination of the universities' identities as formulated through semiotically remediated, that is, repurposed (Prior and Hengst 2010) historical, cultural, political and social discourses on their homepages. The idea was to explore the different everyday sociocultural practices and historical and ethno-political affiliations have been repurposed and 
re-used as semiotic resources for the universities to construct differing identities on their homepages.

To this end, the university homepages were retrieved from their websites and analysed, using selected multimodal discourse analysis tools (Kress and van Leeuwen 1996, O'Halloran, 2004). O’Halloran (2004), Bolter and Grusin (1999), Prior and Hengst (2010) and others have highlighted that with the affordances that the new technological developments in software and editing tools have facilitated, writers and producers are easily able to manipulate verbal and non-verbal signs, and to combine different media for communicative effect. By the same token, multimodal discourse analysis enables one to disambiguate the various semiotic materials used in the construction of a particular message, and identify why particular media or hybrid media were selected and others not, to carry a particular message in a particular context of communication.

Multimodality refers to the diversity of semiotic resources of various kinds that co-occur, interplay and get deployed in the work of textual meaning making (Kress and van Leeuwen 1996). While language is one of the modes through which thoughts, ideas and feelings are represented in a culture, images are another mode. Media and communication specialists combine language and images to achieve optimum communicative effect. They have come to conclusion that language requires reference to other systems to make optimum sense of the world. In short, multimodal discourse analysis emphasises the decentring of language as a favoured tool of meaning making as both language and images are understood as meaning-making modes in our semiotic system.

Iedema (2003) and Bolter and Grusin (1999) have extended the notion of multimodality by coming up with concepts of resemiotisation and semiotic remediation, respectively. Resemiotisation addresses the ways that meaning making 'shifts from one context to another context, from practice to practice, or from one stage of a practice to the next (Iedema 2003: 48). The relevance of the concept of resemiotisation is in determining the mobility of linguistic and visual semiotics as messages get circulated assuming different forms and modalities. This includes capturing how practices manifest intersemiotic shifts when semiotic resources change shape and meaning as they traverse across modes of presentation (Iedema 2003). When these semiotics are being used for purposes that they were originally not known for, then we have what Bolter and Grusin (1999) call semiotic remediation or repurposing. Resemiotisation and repurposing lead to recontextualisation of semiosis, since recontextualisation involves shifts in meaning and materiality away from their previous instantiations to a new context to achieve new meaning and communication purpose (Bernstein 1990). In this regard, we shall see how government's discourses of transformation and images of celebrities and struggle heroes, for example, acquire new meaning as they get recontextualised in the process of the universities rebranding and redefining themselves.

In this paper, a systematic analysis of visual grammar helps to show the universities as active participants in the choices they make regarding the linguistic and non-linguistic 
modes used to construct differentiated brand images for themselves. The paper adopts multimodal discourse analytical tools to examine how the various semiotic resources are resemiotised and repurposed to make meaning in the new contexts, leading to semiotic material being recontextualised in the process of identity rebranding by the universities in question.

\section{Rebranding and recontextualisation of semiosis at South African universities University of the Western Cape}

University homepages, as noted by O'Halloran (2004), normally have the generic layout of masthead in the topmost position with various texts and hypertexts below. The homepage of the University of the Western Cape (UWC) does not conform to this structure. Instead it takes the structure of a formal letter, as it starts by providing its crest in the top right-hand corner followed by its contact details. This crest is in what Kress and van Leeuwen (1996) depict as the Ideal (top of frame) and contains the name of the university and its contact details. In addition, the university has a masthead, which is positioned distinctively, slightly below the subject line (of a formal letter).

In the salutation line are the words 'Welcome to the University of the Western Cape Online'

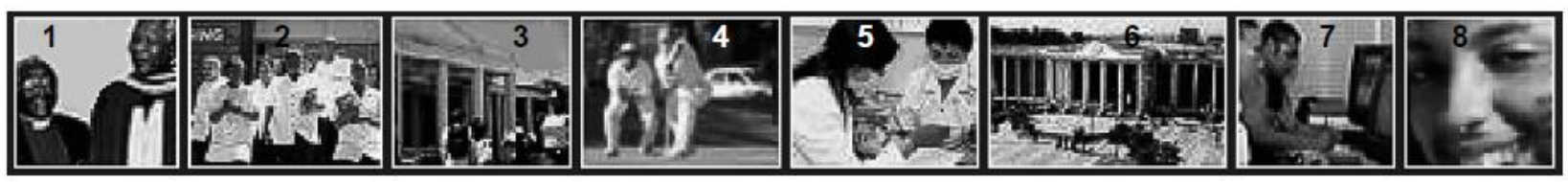

Figure 1: University of the Western Cape's masthead

(see Figure 1) in bold letters, functioning as a salutation to readers. Apart from serving as a welcoming message to the viewer, it also foregrounds the discursive construction of UWC's institutional brand, which becomes visible when one reads both the verbal and visual semiotics in combination as elaborated below. The masthead is a combination of several different pictures joined together as one. It is in a pictorial and sequential form, which conforms to the 'classificational' visual structure as people and buildings are arranged together in a particular visual space in order to show that they belong to the same class, order or category (Kress and Van Leeuwen 1996: 81).

By using the different semiotic resources available in the hypertext environment, the university creates a sense of dynamism and changeability of the UWC brand through relocating the masthead horizontally. The purpose of this homepage is thus circumscribed by the situational and cultural demands of the transformational context. The context here thus stands as a very important aspect that reveals the brand identity UWC is painting. With this in mind, it is quite evident that the pictures in the unique pictorial masthead as shown in Figure 1 are deliberately selected to portray a particular identity.

Following Kress and van Leeuwen (1996), we want to argue that the images on the masthead can be read like a narrative dependent on the reader's familiarity with the people 
or the visuals in place. Elements of the discursive construction of UWC's brand are evident in the eight pictures representing eight stories or socio-histories, which are arranged in such a way as to reveal a particular order of discourse. Photograph 1 shows the former president, the late Nelson Mandela in a graduation gown and former Anglican Archbishop Tutu (a former UWC chancellor) in a jovial mood. The emplacement of the picture (Scollon and Scollon 2003, 2005) in dialogicality with the others in the intersemiotic chain (Iedema 2003) is designed to carry the super-ordinate participants, who are related to a number of other subordinate, lower-level participants in the hierarchy of the categorisation. This taxonomy display is overt as it includes the super-ordinate participants in an explicit manner (Kress and Van Leeuwen 1996, Unsworth 2001). However, this picture is the departing point in the discursive construction of struggle credentials and transformation agenda, which the rest of the pictorial masthead carries and in turn is claimed as UWC's exclusive brand. The picture is anchored in such a way that explicit contact is established with the viewer, who is invited to engage interpersonally with the represented participants. This is because Tutu and Mandela (photo 1) are shown close-up (Kress and van Leeuwen 1996), with every detail of their appearance captured, including their facial expressions (smiling faces). This type of shot (close up) and angle (frontal) helps to reveal traces of their personality and make the viewer feel more intimately acquainted with them (Kress and Van Leeuwen 1996). The close up, frontal framing and positioning of this photograph therefore has the effect of showing the affiliation that UWC has with the two icons and of inviting the viewer to be part of the democratic environment the university finds itself in. Re-branding itself in this way enables UWC to claim struggle credentials and as being part of the transformation agenda, the theme of which is further developed in subsequent the photographs.

As a way of mirroring its social discourse UWC subtly chose the photograph of black high school children (photo 2) shown in a medium shot, thereby depicting their relationship with the viewer as of a social kind (Kress and Van Leeuwen 1996). Photograph 3, which shows one of the university buildings and few students, complements photograph 2, as it shows the high school children now as students who are part of the university. The two prominent national and international icons (in photo 1) are therefore the departing point of the general identity UWC wants the ergodist to view it as having. As these two represent not only the struggle against white domination, but also democracy and freedom in the new South Africa, they bring in with them the formally marginalised black learners (photo 2) to be part of UWC shown in photo 3. In this way, UWC takes centre stage in the assimilation of the previously marginalised groups into higher education, thus helping to address the social ills of the country, especially those rooted in a racially segregated past. Although this is a good initiative, it shows that whites are still not part of this university, which is still undergoing transformation.

As integration is one of the major keys to success in the transformation process, UWC uses the photographs placed in the centre (4 and 5) as the unifying factor of the margins, which also provide the contextualising information. Photograph 4 is an iconic long shot of cricket players facing the viewer. Besides showing what UWC offers, in the South African 
context, sport draws all the other racial groups to be interactive as audience. As such, in the UWC set up, it also works as an inclusive device in which all these races are part of the transformation process. Therefore, in this particular case, UWC uses cricket as a social discourse that unifies all the races to become one as they are all welcome to pursue another important social aspect at UWC, shown in photograph 5, namely, education. The photograph of dentists at work represents this education. UWC's Faculty of Dentistry is the largest in Africa.

Photograph 6 represents the UWC landscape as a vast university in which everyone can be developed academically, as can be seen in photograph 7 in which a man is using a computer to represent his competence to function in the global world in which UWC is operating. Photograph 8 shows a smiling face denoting the new educated generation achieving its academic goals at UWC. This final photograph complements the first one that depicts the old generation bringing the new generation of South Africa new life.

A final point to note about all the images in this band is that they are on the same eye-level with the viewer. This encodes a relation of equality with equivalent levels of power for the viewer and the university (see Almeida 2009: 492). It also signifies the egalitarian environment of the university.

In trying to make sense of this masthead, we also considered Bernstein's (1990) concept of recontextualisation, which is defined as a representation of social events, which he extends to relocation of a discourse from its original context or practice to its reappropriation within another context or practice. The masthead shows that the university has appropriated the discourse of 'the liberation struggle' and repurposed (Prior and Hengst 2010) it for branding and marketisation. As Bernstein (1990) comments, what one sees globally is the on-going appropriation of nationalistic discourse into local contexts. Nationalistic discourse here generally is denoted in the pictures in the masthead as they create the objects they speak about. The political discourse (both on the war of liberation and democracy) has been reconstituted through the images of Tutu and Mandela. The aim is to link the struggle, as well as the nationalistic and democratic attributes associated with the two iconic freedom fighters to UWC's own cause. Whilst claiming this historical link to the national heroes who were part of the oppressed is a good stance, it still shows that not all racial groups are represented in such identity construction choices.

The webpage of this university can also be analysed in terms of Hall's (1990) view that identities are created through imagination. Drawing on Anderson's (1983) notion of imagined communities, we argue that UWC, through a careful selection of images and texts, together with its brand options, has constructed a nationalistic and non-racial community. In this regard, the images in particular function to give a sense of immediacy and make the brand identity more visible and locally relevant.

We should hasten to note that the UWC homepage has not experimented with many of the semiotic resources available. For instance, the stark, white background makes the 
masthead appear like a letterhead, while the standard layout of homepages can be said to foreground credibility at the expense of 'playfulness' (O'Halloran 2004: 146). This makes the homepage more conservative than the other homepages below.

Regarding the organisation of the linguistic and visual instantiations of the webpage, we note a particular trend. For instance, in Appendix 1, just opposite the masthead pictures on the left side, the formatting is left justified with meaningful words aligned from the same vertical point of departure starting from the left. This left justification relates to the reading practice associated with the formal Western reading pattern, which moves from left to right and then proceeds to the next row or line below throughout the text (O'Halloran 2004). In addition to this, UWC only uses the English language on its web page. This monolingual stance could generally be viewed negatively as the institution promotes itself as multicultural and multilingual. However, according to Cenoz and Gorter (2009), even in multilingual contexts, where languages are not contested, the linguistic landscape is likely to carry one language. This is in contrast to contested spaces as portrayed by the SU and UCT homepages below where there is more than one language. We shall elaborate on this in due course.

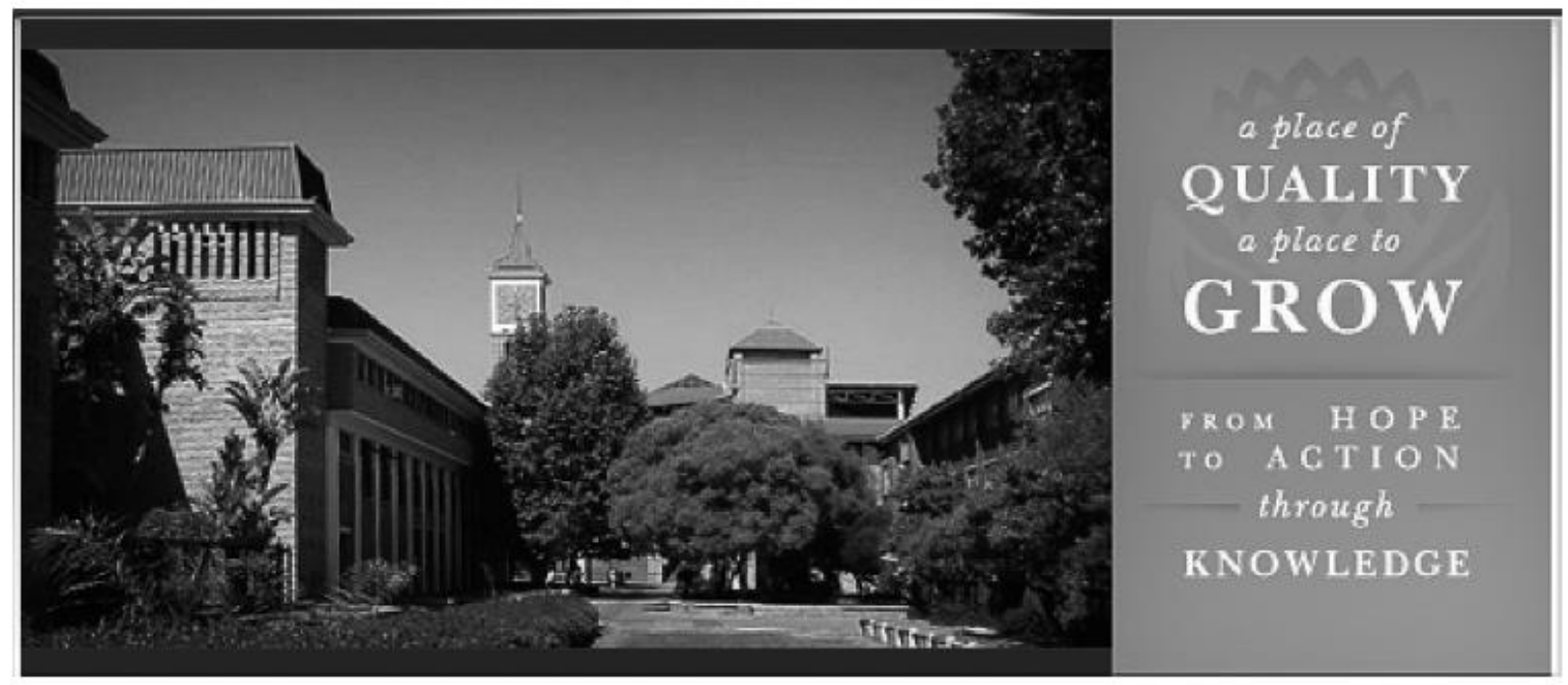

Figure 2: UWC's new slogan

Images in landscape, as seen in Figure 2, have become an integral part of identity construction and the rebranding process. We see the visuals and the verbal co-articulating a brand identity.

The slogan, which is now, represented by the descriptive words 'a place of quality, a place to grow, from hope to action, through knowledge' echoes the visual and architectural semiotics in the image. This change and growth from a 'bush' college to a modern national university in the democratic era is symbolic of the transitions in the continuously repositioning or rebranding as the university takes the lead to heal the nation, and to 
compete on the same level as other universities. The absence of the pictorial masthead also shows how the historical discourses are now being blurred by forces of globalisation.

\section{The University of Cape Town}

Like UWC, the University of Cape Town (UCT) also uses English exclusively as the language of business at the university. However, UCT extends the inclusive agenda by drawing on discourses on multilingualism and other semiotics on its homepage. Despite this, the salutations in three languages spoken in the Western Cape fall short of extended and meaningful narratives in the languages. Thus, it appears, the use of three languages is merely for re-branding purposes as UCT tries divesting itself from the past where it was associated with a white, English-speaking clientele only. It could, however, also be seen as a symbolic gesture towards government language policy, which seeks to promote multilingualism.

Like UWC, UCT begins with revealing its name on the logo, which is positioned on the top left corner of the page, as can be clearly seen in Figure 3, and hence poses as the Ideal. Additionally, the logo, which reveals the name of the institution in three different South African languages (English, Xhosa, and Afrikaans), represents a certain ideological position that UCT is trying to portray.

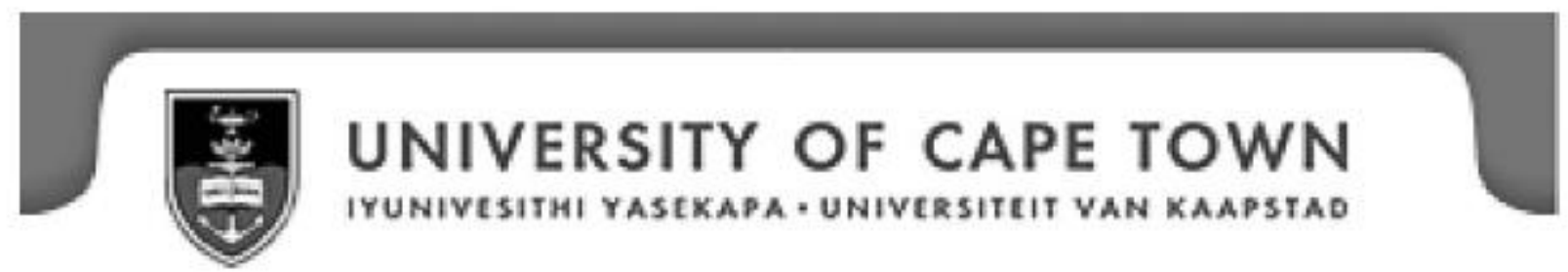

Figure 3: University of Cape Town's logo and slogan

Wells et al. (2003) cited in Osman (2006) emphasise that academic institutions create bold slogans, which are realistic enough to attract prospective students, as they are created based on sound advertisement practices. The UCT slogan which reads as 'Spes Bona' a Latin phrase which means 'Good Hope' is ideally short, clear, and easy to remember (see Well et al. 2003). Thus, the logo with three embedded official languages (English, Xhosa and Afrikaans) of the Western Cape Province and its emplacement as the Ideal is a discursive construction of a new UCT brand, which is also designed to paint the brand as more desirable by revealing its commitment to accommodate diversified groups in the country. Unlike UWC's monolingual brand identity depiction, UCT symbolically acknowledges the multilingualism and by extension, multicultural and plural identities in South Africa. However, we want to argue that whereas UCT uses languages as points of departure in rebranding and identity construction, UWC depicts its diversity through the use of appropriate photographs in its masthead as illustrated in Figure 1. This way of branding 
themselves echoes Bulotaite's (2003) assertion that the purpose for universities to venture into branding is not to try to sell a product or service, but, instead, as (Fairclough 2003) contends, to communicate an identity. In turn, this rebranding gives the universities a platform from which they can compete with other similar universities by differentiating themselves. This kind of rebranding at UCT is particularly important in South Africa's current transition, as it positions the university as forward-looking and neutralises the negative aspects of its historical identity.

Therefore, branding identity is as Aaker (1996) asserts, aspirational in the sense that it shapes the identity and how it should be perceived. As the purpose of branding efforts by universities should be to communicate their identities rather than to sell their products, university branding can therefore be seen as a useful strategy in contemporary South Africa to attract students and stakeholders. In this repositioning, UCT cultivates a unique brand through foregrounding English as its main language both on its logo and on its homepage. Therefore, it subtly deconstructs its old identity by adding the other languages to show its commitment to diverse cultures and its unification in purpose in redressing the inequalities of the past, as well as the changing political and socio- economic environment in which it functions. It is however noteworthy that this kind of embracing of diversity also reveals the linguistic inequalities that can be traced back to majority speakers of the languages concerned. The placing of isiXhosa second followed by Afrikaans, perhaps inconsequential, is nevertheless symbolic of the recognition of fostering integration by ushering the once marginalised groups, especially black students, onto the centre stage. This enables UCT partially to claim some measure of the transformation agenda as its own.

Furthermore, the logo reveals a recurring pattern as the university's name is repeated in the three different languages and this emphasises the brand. Thus, it ensures that the name is not forgotten easily. Drawing on Wernick's (1991: 181) contribution that 'promotion crosses the line between advertising as it is applicable as well as to activities beyond the [immediate] commercial', we argue that UCT draws on the three languages to bring into focus an inclusive brand that is designed to appeal to the people of the Western Cape, South Africa and the world at large. Whether this is successful or not, could be another research topic. What is important here, however, is the interesting stance UCT has taken in rebranding its identity in order to be part of the transformation process of the once racially segregated South Africa. This image mirrors the subtly selected paradigmatic choices used in presenting an acceptable identity in new South Africa. Wernick (1991: 84) asserts that promotion is a communication that is 'defined not by what it says but by what it does.' We argue therefore that this logo was constructed primarily for promotional reasons, which are not necessarily business-related, but rather as a form of social intercourse that is regarded as an important contribution towards building a favourable brand in the South African context.

Similarly to UWC, which repurposed (Prior and Hengst 2010) its visual and architectural features through recontextualising them in the promotional arena, UCT also uses the landscaping features of some its buildings to build its masthead. This is shown in Figure 4. 
This masthead shows the unique, classy buildings and greenery that characterise UCT. It also works here as the UCT salutation, which has the three languages, repeated to welcome the potential customer. The masthead is also the most salient part on the homepage and it foregrounds UCT's prestigious brand identity. The buildings shown on the masthead are placed in a 'frontal angle', thereby inviting the viewer to become part of the world depicted in the brand image (Kress and Van Leeuwen 1996).

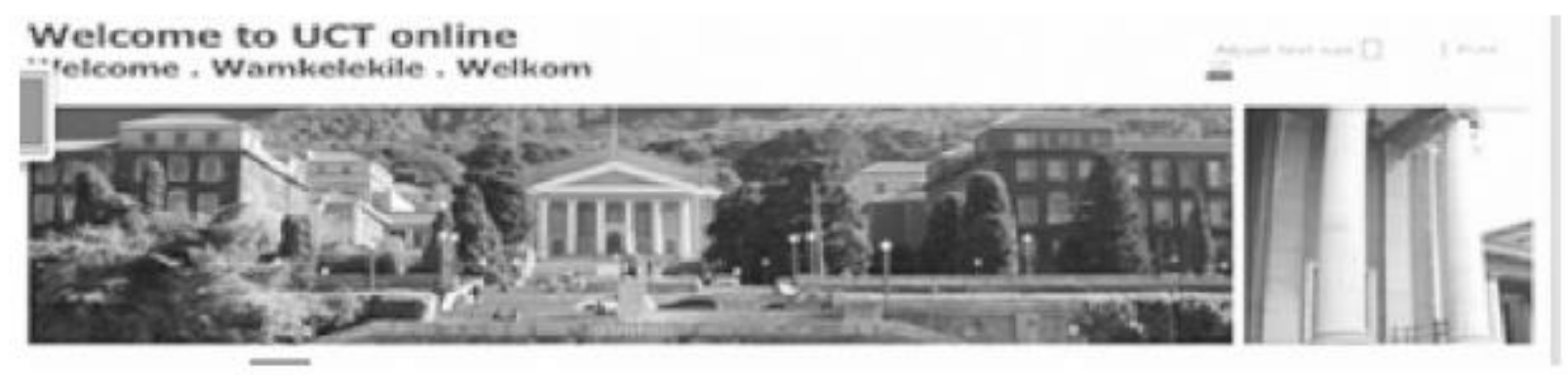

Figure 4: The UCT masthead

In this respect, it is important to note that this angle paints a friendly environment of diverse students interacting, designed to be inclusive of all the races seen in the image (on a closer look). The images are extended to the centre and left, and are inseparable. The way they are used can symbolise that UCT is using its masthead to portray itself as a unifier of South Africa's diversity. In addition, there is a sense of connection through the use of similar colours (e.g. light blue, grey and brown) and the overlapping of the buildings without clear demarcation (absence of framing).

As a way of complementing the prestigious brand identity, the rest of the home page (see Appendix 2) shows the events and notices at the university as the Given, while the centre carries the latest, most important information (see Kress and Van Leeuwen 1996). The discursive construction of UCT's international research and development credentials is seen from the amount and value it attaches to academically prestigious stories on its homepage that are related to the UCT brand it attempts to create. This is different from the UWC homepage that foregrounds news that draws on both societal and academic activities.

In addition, the New position (Kress and Van Leeuwen 1996) (right side of homepage) has different types of discourses, such as the health discourse, the weather discourse, and interestingly, the heritage discourse. The presence of the heritage discourse differentiates UCT from the other universities in this study, as it has a unique type of what it considers as heritage apart from the new national considered meanings (see Appendix 2). It highlights that heritage is dynamic and evolves with time. Given its age, it has many symbols that relate to its heritage. It however acknowledges that it has to match the present social and political change landscape. Placing this information as the New shows that UCT wants to be seen in that light, which is not a familiar move in the new democratic transition. To a certain extent, it indicates that UCT, as a previously white university, is changing to fit into the 
new egalitarian dispensation. It shows here that UCT's intent is on maintaining its brand as a methodical and traditional university. This new strategic rebranding echoes Stensaker's (2005: 6) assertion that branding is also regarded as a phenomenon that allows individual academic organisations to provide information and images that combine neutral information with information intended to create emotional ties between various stakeholders and a given institution.' This is because it is important for any university to have a positive image or brand to enable it have a positive impact on the recruitment of students and academic staff, for attracting resources, and to create goodwill (Belanger et al. 2002). However, these brands are increasingly tested and contested, in the sense that society and various forms of national independent evaluation or media investigations may to some extent hold institutions responsible for images that are not rooted in reality. Therefore, the results of being caught on the wrong side can be damaging (see Stensaker 2005), not only ethically or legally (Belanger et al. 2002), but also in terms of resulting in poor levels of student applications or high dropout rates (Levitz et al. 1999). Because of this potential for low registration numbers and high dropout rates, it is strategically important for universities, such as UCT in this case, to create brand images that match their organisational brand identities. Hence, in a changing South African environment, UCT's rebranding challenge as an academic institution is to strike a balance between adjusting to a changing world, while, at the same time subtly maintaining its 'traditional' brand identity. This is also true of UWC, which in spite of foregrounding transformation and transnationality has retained its struggle credentials. In the next sections we show how Stellenbosch University, similarly, holds on to its Afrikaans heritage while embracing transformation.

\section{Stellenbosch University}

On its homepage shown in Figure 5, Stellenbosch University (SU) introduces itself in a unique way compared with the other universities in this study. It has packaged the details most pertinent to its repositioning on one main resemiotised image, presented as a beautiful landscape.

Its uniqueness is revealed through the stylised ' $U$ ' and ' $S$ ', which forms an emblem, with the university's name alongside in two languages: Afrikaans (Universiteit Stellenbosch) and English (Stellenbosch University). As shown in Figure 5 (A), the name is in a hierarchy, indicating Afrikaans as the dominant language at the university. Nonetheless, these languages (Afrikaans and English) are two of the three languages used in the Western Cape Province where the university is situated. Unlike UWC, which opted for monolingual signage, and UCT with symbolic multilingualism, SU uses Afrikaans and English extensively in successive hypertexted homepage.

As can be seen in the salutations, SU welcomes clients in English first, then in Afrikaans, and these greetings are separated as two single entry points into the import (see B in Figure 5) above. By using English first, followed by Afrikaans in this bilingual salutation, it could be said that this shows that SU may be attempting to offset the fact that Afrikaans was put first when naming the university, thus attempting to create language equality locally, while, 
at the same time, taking into account the globalised world. In respect of the latter interpretation, it shows that SU has conformed to the pressure of a globalised world in which English is the main lingua franca, thereby attracting the world community and assuring it that SU is accommodative. Nonetheless, as noted above, the use of two or more languages in a linguistic landscape may reveal a contested space in which speakers of a particular are not ready to give ground. Indeed, although there have been no debates on the language of instruction at UCT and UWC, SU has seen heated discussions as to whether it should retain Afrikaans, switch to English or use both languages (Oostendorp and Anthonissen 2014). Although there is a kind of 'ceasefire' among interest groups, the debate still continues in the background. However, a consideration of how the placement of the Afrikaans texts function holistically shows that Afrikaans is the main language preferred by the university. Therefore, as mentioned above, SU subtly maintains its identity as an Afrikaans university.

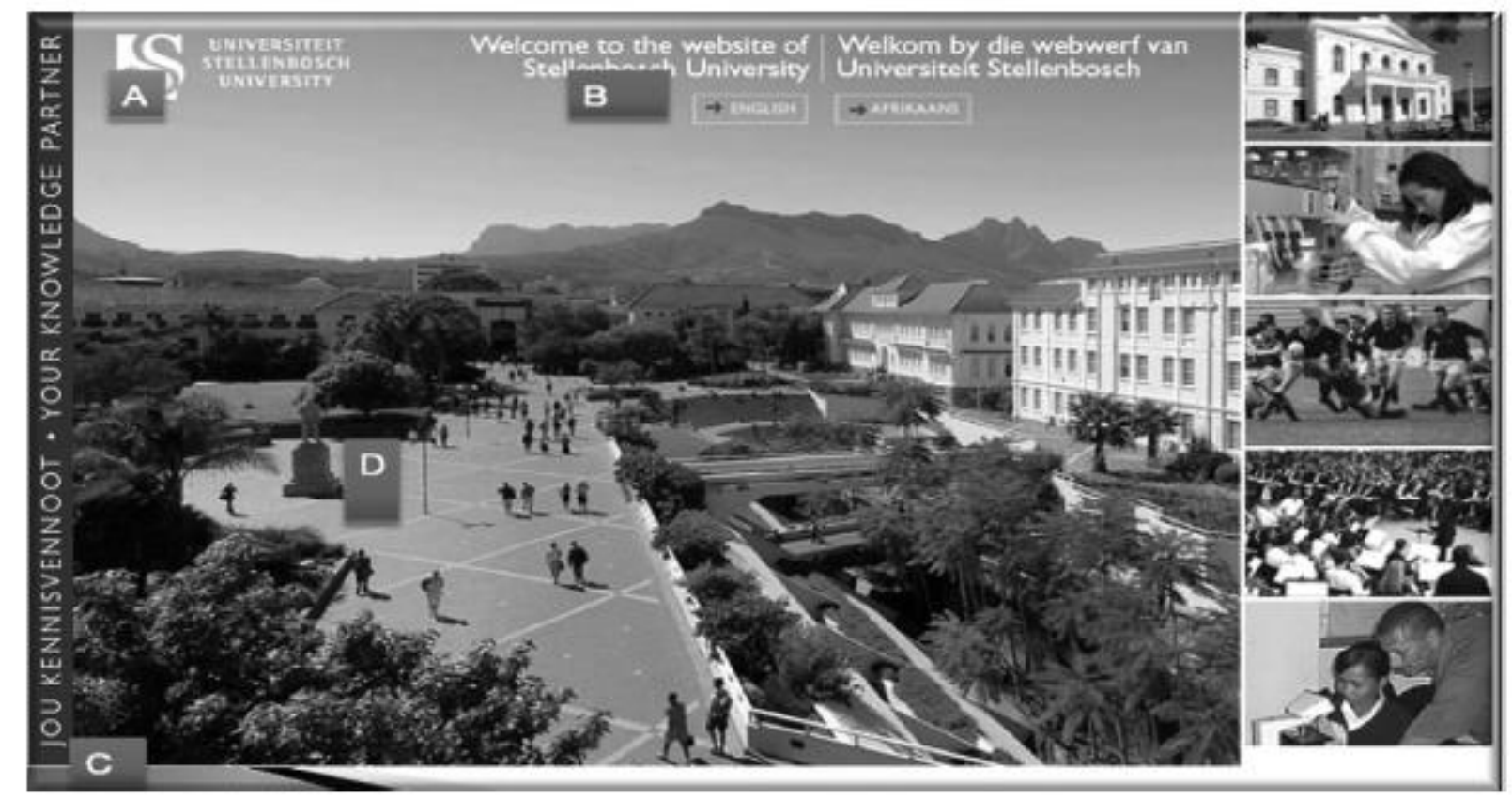

Figure 5: Stellenbosch University

The brand slogan on the far left of the landscape, positioned in a vertical line (see $\mathrm{C}$ in Figure 5), functions as the Given. It reads: 'JOU KENNISVENNOOT. YOUR KNOWLEDGE PARTNER'. Although the juxtaposition of the two languages appears to amplify the gulf between Afrikaans and English interests, leading to 'double monolingualism' rather than to an expression of integration and harmonious relationships, this slogan does have positive benefits. For example, it uses the literary technique of aptness and boldness (see Osman 2006) and it acts as a punchline, which is strong and effective, and can be remembered easily (see Osman 2006). The overall layout of the homepages suggests that SU has experimented with the different semiotic resources in the hypertext environment to create a sense of dynamism and unpredictability. For instance, as can be seen on this 
homepage, SU flouted convention by duplicating the slogan in two different languages and relocating it vertically down the left side of the homepage. This manner of formatting also contradicts standard Western reading convention, as the reader has to read the slogan from the bottom upwards (see O'Halloran 2004). This positioning of the slogan is done by design in order to emphasise SU's Afrikaans brand identity, as one is forced to 'read' the Afrikaans slogan first.

Colour also plays an important role in the re-creation of SU's brand identity. This is seen in the way that SU employs light blue, purple and white as the main colours for its homepage. These colours are interpreted in the literature as signifying the truth, wealth and royalty, and comprehensiveness, respectively (see Kress and Van Leeuwen 1996). We are mindful, however, that these meanings cannot be generalised to every context, including, especially, this webpage. This is because people in different contexts interpret these colours differently. Consequently, instead of the interpretations offered above, these colours can also be interpreted here as connective devices, which, by linking and grouping the various elements on the homepage, provide it with coherence.

Similarly to UWC, which used the group identity of a pictorial slogan to claim the transformation agenda as its own, SU also draws on the distinctive photographs positioned on the far right of the homepage as the New, in order to reflect its repositioning in the changing South Africa (see Figure 5). The first photograph in this vertical row is the main image. It shows SU's beautiful buildings, followed by a photograph of a scientist carrying out experiments. The juxtaposition of these first two images co-articulates the verbal text in the mission statement that SU is an outstanding scientific research institution. The style of architecture is important (has connotations of grandeur, classicism, permanence, etc.) and the gender of the scientist also has its own connotations in terms of SU's repositioning from an Afrikaner, patriarchal institution to one that acknowledges 'non-sexism' enshrined in the Bill of Rights.

In addition, there is a photograph of the national rugby team on this homepage. Since this team is regarded as prestigious because it has been dominating the sporting arena nationally and internationally as champions for several years, SU associates itself with the team, thereby appropriating connotations of excellence, success, commitment, and so on all qualities associated with the team - in painting an identity for itself. Just as in the case of UWC, SU also uses sport (rugby in this case) as a unifying factor. The last two photographs show that marginalised groups (racial groups that were not allowed to register at SU during apartheid) have - to some extent - been allowed some form of inclusion in the university, such as through SU's outreach programme and its limited acceptance of black students. The marginalised group's presence signifies SU's effort to accommodate them, thereby taking on a stance in the identification process, which can also be seen as a way of US claiming the transformation agenda as its own. In this way, SU cleverly neutralises the brand identity of it as a 'white' Afrikaans university by depicting scenes that illustrate its acceptance of inclusivity. 
SU also takes advantage of its geographical location to highlight its identity as an attractive university. This is seen in the main landscape photograph, which encompasses a wide range of beautiful, old and unique buildings, as well as attractive greenery, both of which function as the face or outlook of the university. This view of SU was captured at an angle designed to reveal the magnificent mountains that are some distance behind the university. This positions SU on the market in terms of tourism as well. By doing this, it claims 'economy credentials.' In addition, the scale of the whole picture heightens prominence of landscaping and this serves as the focal point through which the web is entered. Even the slogan, which is in non-conventional font and capital letters, is a deliberate choice that makes it stand out from the rest. Osman (2006) points out that in particular, public universities use slogans because of the effect of the changing university culture. This aspect is very interesting, especially when looking at how this university has crafted its unique slogan, as well as the type of images and colours used on the homepage. The contemporaneous environment is used to co-articulate its identity. Thus, one can say that SU has achieved a prestigious brand by means of the resemiotisation on the recontextualised landscaping. Coupled with the new attributes that SU has appropriated, its identity is further enhanced by the recontextualisation of resemiotised historical artefacts, including buildings and statues. Though originally built for white Afrikaner students, all race groups that enrol in the institution now enjoy the SU buildings. Similarly, the statue of the 'benefactor' Jan Marais (labelled D in Figure 5) watches over not only white students, but also all other racial groups that pass under it. What we get, therefore, is $\mathrm{SU}$ is subtly maintaining connections to the past while - to some extent embracing social transformation and the new global realities.

\section{Concluding remarks}

In the preceding analysis, we indicated that rebranding has enabled the universities in the study to create convincing structures as a response to new demands in their environments while protecting their core values (see Mintzberg 1983). The three universities have developed brands that are simultaneously distinct and recognisable. They showcased particular traits of a corporate brand identity, which encompassed highlighting high-quality research and academic credentials, as well as a national and an international reputation. This is necessary as South African universities have to compete with each other and internationally in order to attract high-quality students and academic staff at both a national and an international level. Their respective homepages also indicated a recognition that competition is no longer limited to a particular race or to national borders, but applies across races and internationally.

All three universities analysed in the present study used the semiotic landscapes at their disposal to paint attractive brands on their homepages. The concept of multimodality was very useful in disentangling the semiotic resources of various kinds that were coarticulated to construct the different brand identities. We have shown how the homepages blended cultural semiotic artefacts, historical, postmodern (globalisation) and transformation discourses and architectural landscapes to construct different identities and brands for the universities. This demonstrates how multi-semiotic modes and designs can 
be made to co-occur and augment each other as forms of meaning making. It also shows how the universities' identities have been socially constructed to suit their everchanging environments.

It was evident that recontextualisation and resemiotisation as concepts in MDA are not only treated as representations of social events, but also as the appropriation of discourses and semiotic resources by institutions, to create global competitive brands with local relevance. The universities appropriated and used different semiotic resources in repositioning themselves and to be in line with the government's transformation agenda after the demise of apartheid and racialised education.

We conclude therefore that the universities have rebranded themselves through repurposing the transformation discourses and images to recast themselves as deracialised, egalitarian and altruistic institutions of higher learning. We saw how they used website design tools to emplace appropriate images in opportune positions of the homepages to back up their claims of racial harmony, academic excellence, cutting-edge research capacities and modern infrastructure.

However, this conclusion needs some modification, since the study suggest that in unpacking transformation, the universities do not always do justice to the government's transformation agenda. There is a sense that their transformation discourses appear to be used for branding purposes rather than for solving or reducing inherent and inherited socio-economic inequalities in South Africa. For instance, the inclusion of isiXhosa on the UCT homepage is limited to a symbolic greeting in the language. In addition, the homepages - perhaps inadvertently - exemplify a number of inherent contradictions or unresolved tensions. For example, transformation on these three homepages is constructed as integration, inclusion and unification in diversity. However, the apparent contradiction in how to achieve integration while attaining diversity is not resolved in these homepages. The other unresolved problem relates to the universities constructing themselves as rainbow institutions to showcase their transformation in the face of inherited inequalities in society and among the student populace itself. Our argument is that this view of transformation being constructed glosses over serious inequalities, tensions and racial debates that are still raging in South Africa. 


\section{References}

Aaker D. 1996. Building strong brands. New York: Free Press.

Almeida D. 2009. Where have all the children gone? A visual semiotic account of advertisements for fashion dolls. Visual Communication 8(4): 481-501.

Anderson B. 1983. Imagined communities. Available at https://www2.bc.edu/mariansimion/th406/ readings/o420anderson.pdf. [accessed 28 February 2014].

Bawa A, Herwitz D. 2008. South African Universities in the Tumult of change. The Africa Issue 15(2): 1-13.

Belanger F, Hiller JS, Smith WJ. 2002. Trustworthiness in electronic commerce: the role of privacy security and state attributes. Journal of Information Systems 11: 245-270.

Bernstein B. 1990. The structure of pedagogic discourse: class, codes and control. London: Routledge.

Bolter JD, Grusin R. 1999. Remediation: understanding new media. Cambridge: MIT Press. Bulotaite N. 2003. University heritage - an institutional tool for branding and marketing. Higher Education in Europe 28(4): 449-454.

Cenoz J, Gorter D. 2009. Language economy and linguistic landscape. In: Shohamy E, Gorter D (eds), Linguistic landscape: expanding the scenery. New York and London: Routledge.

Fairclough N. 1993. Critical discourse analysis and the marketisation of public discourse: The universities. Discourse and Society 4(2): 133-168.

Fairclough N. 2003. Analysing discourse textual research for social research. New York: Routledge. Gee JP. 1999. An introduction to discourse analysis: theory and method. London: Routledge.

Gerhart GM. 1978. Black Power in South Africa: the evolution of ideology. Berkeley: University of California Press.

Hall S. 1990. Cultural identity and diaspora. In: Rutherford J (ed.), Identity: community, culture, difference. London: Lawrence and Wishart.

Iedema, R. 2003a Discourses of post-bureaucratic organization Amsterdam: John Benjamins Publishing Company.

Jewitt, C. and Oyama, R. 2001. Visual Meaning: A Social Semiotic Approach. In: Van Leeuwen T, Jewitt C (eds), A handbook of visual analysis. London: Sage.

Kress G, Van Leeuwen T. 1996. Reading Images: the grammar of visual design. London and New York: Routledge.

Levitz RR, Noel L. Ritcher BJ. 1999. Strategic moves for retention success: promising practices in recruitment, remediation and retention. San Francisco: Josse-Bass New Directions.

Mautner G. 2005. The entrepreneurial university: a discursive profile of a higher education buzzword. Critical discourse studies 2(2): 95-120.

Mintzberg H. 1983. Structures in fives: redesigning effective organisations. Engewood Cliffs: Prentice Hall.

Morgan G. 1983. Beyond method: strategies for social research. Beverly Hills, CA: Sage Publications.

Lalu R. Murray N. 2012. Becoming UWC: reflections, pathways and unmaking apartheid's legacy. Bellville: UWC Centre for humanities research. 
Odhav K. 2009. South African post-apartheid Higher Education policy and its marginalisations: 1994-2002 SA-eDUC Journal (6)1: 33-57.

O’Halloran K. 2004. (ed.). Multimodal discourse analysis. New York: Continuum.

Oostendorp M. Anthonissen C. 2014. Multiple voices in bilingual higher education: language choices of Afrikaans/English bilinguals at Stellenbosch University. Per Linguam 30(2): 69-87. Osman H. 2006. An investigation of socio-cognitive strategies in university. ESP Malaysia, 12: 39-51

Prior P, Hengst J. (eds). 2010. Exploring remediation as discourse. Urbana-Champaign: Palgrave Macmillan.

Reddy T. 2004. Higher education and social transformation: South African case study. Avaialble at www.che.ac.za [accessed 21 February 2014].

Scollon R, Scollon SW. 2003. Discourses in place: language in material world. New York: Routledge.

Scollon R, Scollon SW. 2005. Lighting the stove: why habitus isn't enough for critical discourse analysis. In: Wodak $\mathrm{R}$, Chilton $\mathrm{P}$ (eds), A new agenda in (critical) discourse analysis: theory, methodology and interdisciplinarity. Amsterdam and Philadelphia: John Benjamins Publishing Company.

Stensaker B. 2005. Strategy, identity and branding - reinventing higher education institutions. Available at www.nifustep.no/index.php/content/download/16708/95315/file/Paper5oen_ Strategy_identity_and_branding_edited.pdf [accessed 3 August 2009].

Unsworth L. 2001. Describing visual literacies. In: Unsworth L. (ed.), Teaching multiliteracies across the curriculum: changing contexts of texts and images in classroom practice. Buckingham: Open University Press. pp 92-103.

Wells W, Bunnert J, Moriaty S. 2003. Advertising principles and practice. Upper Saddle River, New Jersey: Pearson Education Inc.

Wernick A. 1991. Promotional culture. London: Sage.

Wolpe H. 1995. The debate on university transformation in South Africa: the case of the University of the Western Cape. Comparative Education 312(17): 275-292. 
Appendix 1: University of the Western Cape homepage

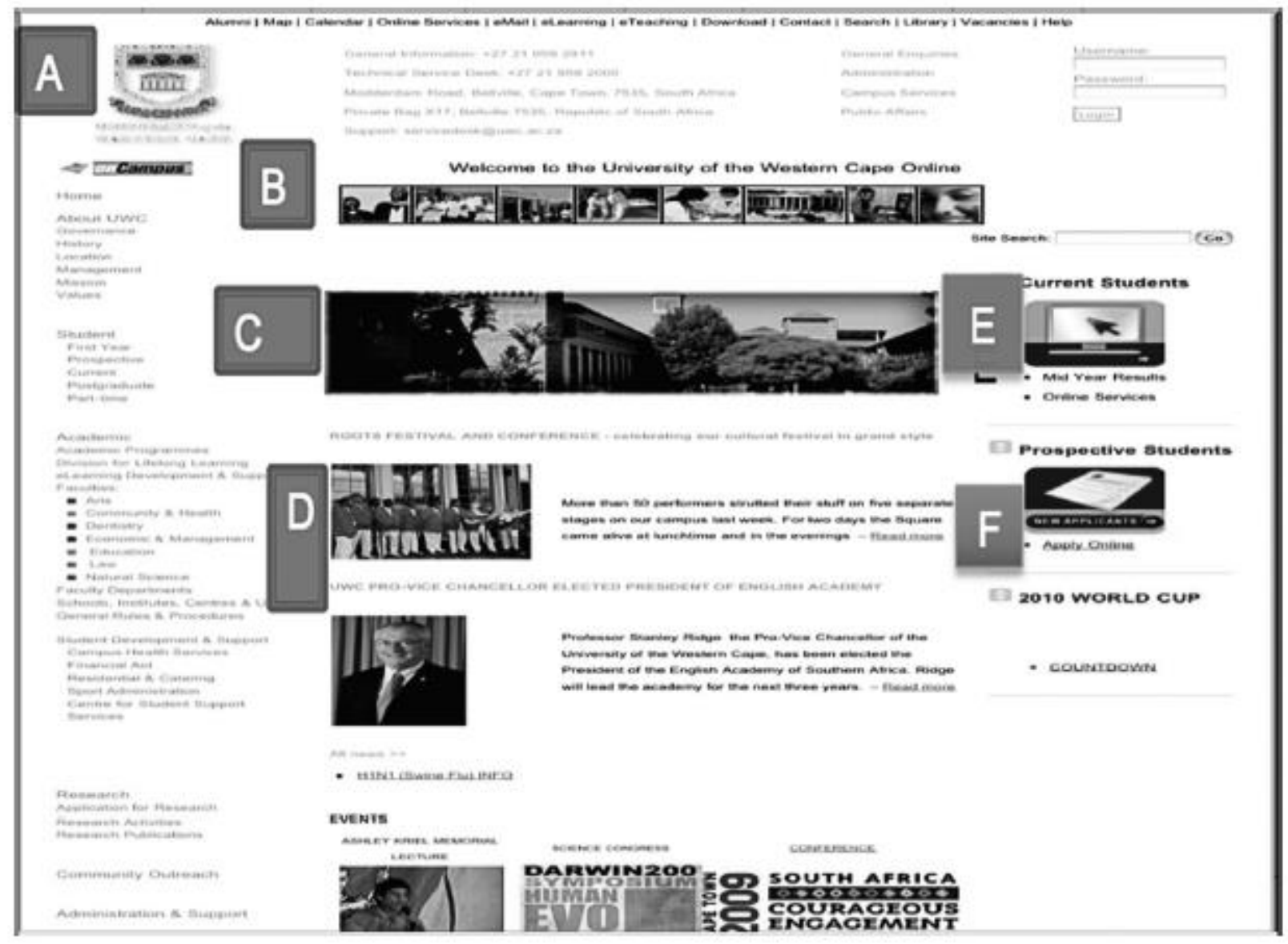


Appendix 2: University of Cape Town homepage

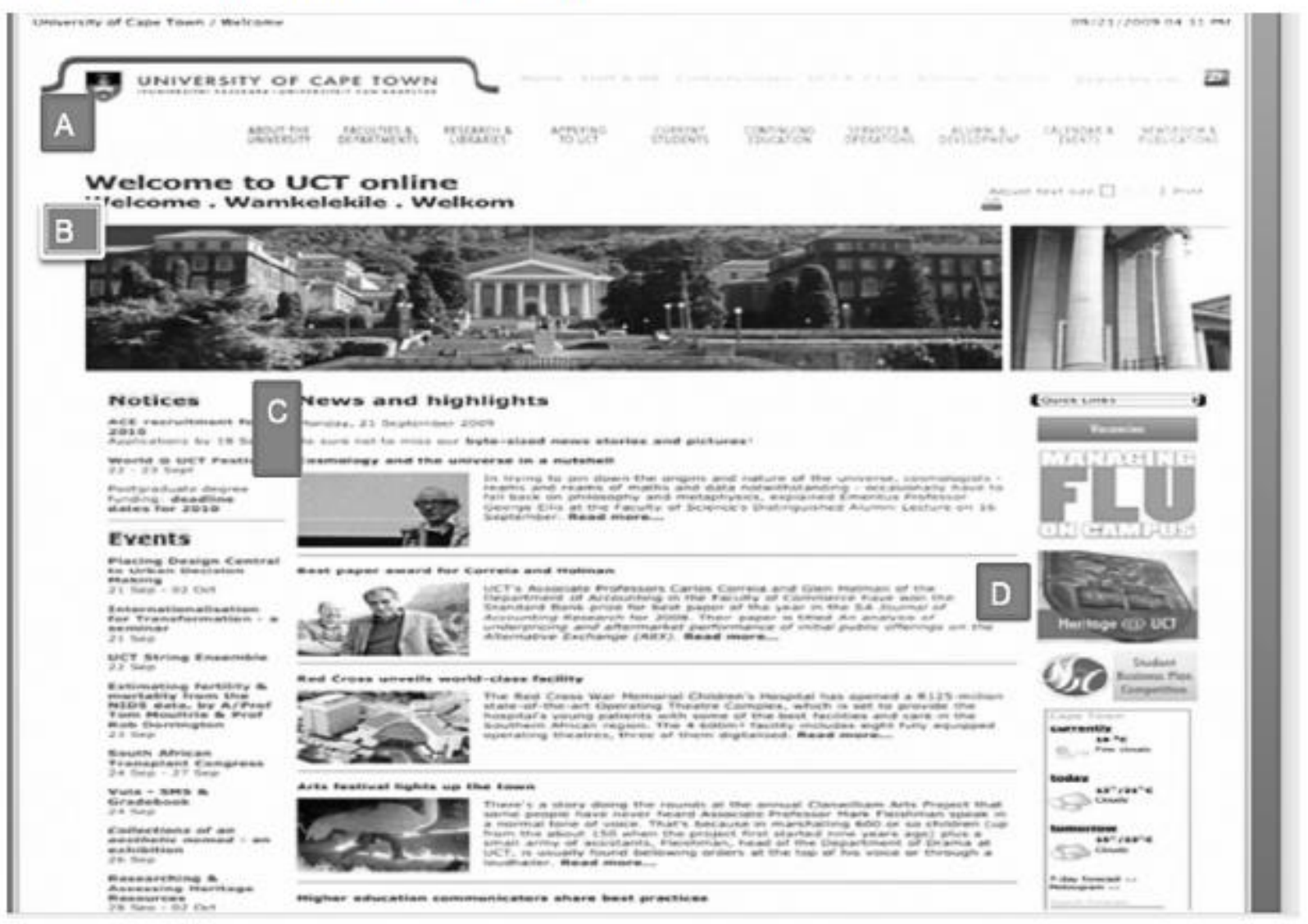

